\title{
Mode of Inheritance of Immunocompetence Traits in Three Japanese Quail Populations
}

\author{
Monika, M. ${ }^{1}$, J.J. Rokade ${ }^{1 *}$, Narayan, R. ${ }^{1}$, Snehasmita Panda ${ }^{2}$, Jyotirmoy Saharia ${ }^{1}$, \\ Mukesh T. Nampalle ${ }^{1}$ and Suchismita Pradhan ${ }^{1}$
}

${ }^{1} I C A R$ - Central Avian Research Institute, Izzatnagar, UP, India

${ }^{2} I C A R$ - Indian Veterinary Research Institute, Izzatnagar, UP, India

*Corresponding author: JJ Rokade; E-mail: jaydeepvet@gmail.com

Received: 17 May, 2020

Revised: 06 Nov., 2020

Accepted: 10 Nov., 2020

\begin{abstract}
In order to assess genetic attributes on immune traits of three varieties of domesticated Japanese quails developed by CARI (CARI-UJJAWAL, CARI-SUNEHERI AND CARI-BROWN) were chosen at random from the base populations and reared in individual cages to maintain sire and dam pedigree record system. Records of 160 progenies from 180 sires and 180 dams of each variety analysis carried using restricted maximum likelihood (REML) animal model. The progenies (480 birds) were exploited to predict the genetic variations in immune traits at $5^{\text {th }}$ (Humoral) \& $7^{\text {th }}$ (cell mediated immunity) week of age. Analysis of data revealed that HA titre values was significantly $(\mathrm{p}<0.01)$ differed among the varieties and also the hatches. Sex had a no significant impact on the immune traits. For foot pad index test, varieties had significant $(\mathrm{P}<0.01)$ effect. But there was no significant effect between sex and also between hatches. Heritability estimates of the immunological traits based on the sire component of variance for antibody titre (HA) ranged from medium to high (0.25 to 0.44), and estimates were low in Foot pad index (0.011 to 0.171$)$ in all the varieties.
\end{abstract}

\section{HIGHLIGHTS}

( Immunity - Humoral immunity, Cell mediated immunity.

( Disease-tolerance- via genetic selection- a desirable approach, genetic parameter- heritability.

Keywords: Immunity, antibody titre (HA), Foot pad index, Japanese quails

The spectacular growth that poultry sector has witnessed world-wide has been predominantly chicken centric. Continued for fast growth and high production among broiler, layer type birds respectively, has narrowed down the chicken genetic diversity to the extent that bulk of the global poultry production relies on just three breeds: White Leghorn for egg; Plymouth Rock and Cornish chicken breeds for broiler production. There too, only a few of the breeding magnates maintaining elite Grand Parent Lines serve as the power source of breeding stock. Crossbreeding of indigenous chicken stocks is an endeavour to strengthen the family poultry farming schemes has further led to the loss of genetic diversity. Alternate or non-chicken poultry raising systems offer an opportunity to widen a resource base for the growing poultry sector and at same time provide alternatives both, to the poultry stock-holders along with consumers. A production and consumption trend over the course of years indicates a hit in volumes in the share of non-chicken poultry species to overall chicken egg and meat production.

Broiler quails are commonly slaughtered for financial motives at within 5-6 weeks (Genchev et al., 2008). Selection of birds for high body weights under modern

How to cite this article: Monika, M., Rokade, J.J., Narayan, R., Panda, S., Saharia, J., Nampalle, M.T. and Pradhan, S. (2020). Mode of inheritance of immunocompetence traits in three Japanese quail populations. J. Anim. Res., 10(6): 1043-1049.

Source of Support: None; Conflict of Interest: None

क 9 
intensive stressful conditions is commonly associated with increased incidence of diseases, which in turn impairs genetic progress in performance traits. Many findings reported increased selection responses in body weight of commercial birds premised on genetic criteria of growth traits, but the immune performances are becoming more vulnerable with expansion in body weight. In commercial production systems, heavy demand for increasing body weight is having negative outcome on the immune traits, primarily in broiler chickens and turkeys (Saatci et al., 2006; Van der Most et al., 2011). Most of the animal breeding plans were predominantly pertained to improve the growth rate because of its ease and cost-effective (Barbieri et al., 2015), whereas recording or genetic appraisal of defence system performances is usually neglected. Immune responsiveness to non-specific, multideterminant natural complex antigens like sheep red blood cells can give a good predictor of the bird's innate immunity. Siegel and Gross (1980) found that a high antibody production line against SRBC was resistant to parasitic and viral diseases and antibody producing ability to non-disease antigens in particular SRBC is affected by genetic diversity. The increasing awareness among consumers on drug residues in meat and the high cost of medicines/drugs used in aviculture suggests that improving disease-tolerance of the birds via genetic selection is the desirable approach. The other advantages of breeding for resistant to diseases are conserve natural resources and avoid repeated expenditure on medicines, vaccines and biosecurity. Inheritance pattern of antibody response and cell mediated immunity is polygenic in nature (Lamont, 1998) and having low to moderate heritability estimates.

Because of the myriad of potential pathogenic organism that might exist in a bird's environment, direct selection for every individual pathogens response is impracticable. Instead, general upgrading of immune response capacities should be exploited as a genetic approach to develop populations that are robust in the face of numerous and varied environmental challenges. Indirect selection based on immunocompetence traits or suitable genetic markers, represents an ideal approach for the improvement of disease resistance (Gavora and Spencer, 1983). The delicate balance between the various constituents of the defence mechanism viz., humoral and cell-mediated immunity (CMI) is necessary to ensure optimum immune function and also production level. This emphasise the need to separately measure and select for diverse facets of immune system, as well as to evaluate the effects of immunocompetence on the traits of economic importance. Many Japanese quail stocks originated from distinctly variant germplasm and presently maintained at Experimental Quail Farm, CARI have undergone several generations of selection for important market traits like growth and egg production. As the response to selection, most of the genetic stocks have elicited significant positive response for meat traits. However the collateral response in survival traits has not been very high. Of late a lot of emphasis is given to boost the immunocompetence status of these stocks so as to improve the overall resistance to diseases. It is therefore required to study the inheritance of immune parameters of these stocks, inclusive of humoral and cell mediated immunities so as to develop suitable strategies to breed quail seed stocks with better innate disease resistance.

\section{MATERIALS AND METHODS}

\section{Ethical approval}

The present experiment was carried out as per the approved protocol of Institute Animal Ethics Committee (IAEC), ICAR-CARI, and Izzatnagar (IAEC approval number: 452/01/ab/CPCSEA).

\section{Source and management of birds}

The data were taken from the Japanese quail population at the experimental quail farm of Central Avian Research Institute, ICAR-CARI, Izzatnagar, UP, India. The pedigree population were descended from 180 sires and 180 dams of each variety (CARI-UJJAWAL; CARI-SUNEHERI and CARI-BROWN) of domesticated Japanese quails (Coturnix japonica) were randomly chosen from the base populations to develop first generation of experimental population. Adult mating pairs were enclosed in individual cages $\left(\mathrm{L}^{*} \mathrm{H}=25^{*} 15 \mathrm{~cm}\right)$ for accurate pedigree identification and performed the breeding. According to the birdcage number, wing banding was done to each bird. The birds had ad libitum access to food and water. 


\section{Collection and incubation of fertile eggs}

Pedigreed and fertile eggs (age of breeder flock -8 to 11 weeks) were taken from all the three varieties twice daily. Each collected egg was numbered, according to its sire and dam therefore, a full pedigree was accessible for each egg. Collected fertile eggs were kept in a room with a temperature of 13 to $15^{\circ} \mathrm{C}$ and relative moisture percentage is of $70 \%$. Every $7 \mathrm{~d}$, collected eggs were sterilised with formaldehyde, placed in the setter for 14 days, and moved to the hatcher for 3 days. The hatcher was equipped with separated boxes to record the pedigree. On the $17^{\text {th }}$ day, the hatched chicks were wing banded and the pedigree details recorded. A total of 6221 numbers of chicks (inclusive of three varieties) were produced from three hatches of 7 days interval. The body weight of the chicks was noted to maintain the pedigree record. The chicks were brought to brooder house and grown under battery brooders with $35^{\circ} \mathrm{C}$ temperature and raised up to 5 weeks of age. After the $4^{\text {th }}$ week, supplemental heating was disconnected. A routine management operation was followed throughout the trial period and was uniform for all the three varieties. Anad-libitum feed and water were given. A balanced quail starter mash was fed up to $5^{\text {th }}$ week. Sexing was done on $3^{\text {rd }}$ week of age.

\section{Immune-response}

Immune responses of the experimental birds were evaluated in terms of humoral ( $5^{\text {th }}$ week $)$ and cell mediated immune response ( $7^{\text {th }}$ week). One hundred and sixty birds (160) birds which are progeny of 40 sires and 40 dams were selected from each variety.

\section{Humoral immune response}

Humoral immunity was evaluated as antibody titre (HA) against $0.5 \%$ SRBC suspension. The microtitre HA procedure (Siegel and Gross 1980) was adopted for evaluating total HA antibody titre in the broiler birds on day 5 th of post inoculation of $0.5 \%$ SRBC suspension.

\section{Preparation of reagents}

The composition of Alsever's solution and phosphate buffer saline (PBS) used in determination of humoral immunity of birds are described below:

\begin{abstract}
Alsever's solution
The Alsever's solution was prepared by mixing dextrose, 2.05 gram $(\mathrm{g})$; Tri sodium citrate dehydrate, 0.80 gram $(\mathrm{g})$; Sodium Chloride $(\mathrm{NaCl}), 0.42$ gram $(\mathrm{g})$; citric acid, 0.055 gram $(\mathrm{g})$ in $100 \mathrm{ml}$ distilled water. The $\mathrm{pH}$ was adjusted to 6.5 by addition of citric acid and thereafter, the solution was stored in refrigerator at $4^{\circ} \mathrm{C}$.
\end{abstract}

\section{Preparation of phosphate buffered saline (PBS)}

The phosphate buffer saline (PBS) is prepared by mixing Sodium Chloride $(\mathrm{NaCl}), 8.00$ gram $(\mathrm{g})$; Potassium chloride (KCl), 0.20 gram (g); Potassium di-hydrogen phosphate $\left(\mathrm{KH}_{2} \mathrm{PO}_{4}\right)$, 0.20 gram (g); Di-sodium hydrogen phosphate $\left(\mathrm{Na}_{2} \mathrm{HPO}_{4}, \mathrm{H}_{2} \mathrm{O}\right), 1.44$ gram (g) in 1 lit of distilled water. The $\mathrm{pH}$ of solution (PBS) was adjusted to 7.20 .

\section{Preparation of $0.5 \%$ SRBC suspension}

Healthy sheep was selected and blood (site- jugular vein) of the same was procured in Alsever's solution. The supernatant obtained on centrifugation (3000 rpm for 5 min) from the collected sheep blood was discarded. The remaining potion (SRBCs) was properly washed three times using PBS. After washing, $0.5 \mathrm{ml}$ of SRBC (PCV) was added in $99.5 \mathrm{ml}$ of PBS to make $100 \mathrm{ml}$ of $0.5 \%$ SRBC suspension and stored at $4{ }^{\circ} \mathrm{C}$ in refrigerator.

\section{Immunization with SRBC and harvesting of immune serum}

Each bird received $0.1 \mathrm{ml}$ of $0.5 \%$ SRBC suspension intravenously. About $2 \mathrm{ml}$ of blood collected from the jugular vein at 5 days post-SRBC immunization. The blood was allowed to clot at $37^{\circ} \mathrm{C}$ for $1 \mathrm{hr}$. The blood then centrifuged at $2000 \mathrm{rpm}$ for 15 minutes and the immune serum was harvested and retained at $-20^{\circ} \mathrm{C}$ for subsequent antibody titres to SRBC testing. The microtitre HA procedure (Siegal et al., 1980) was adopted for evaluating total HA antibody titre in the birds on day 5th of post inoculation of $0.5 \% \mathrm{SRBC}$ suspension.

\section{In-Vivo Cell mediated immune response (CMI)}

The in vivo response to mitogen (PHA-P) was evaluated according to the method described by Corrier and Deloach 
(1990). Phytohaemagglutin type P (PHA-P) derived from the 'red kidney bean, Phaseolus vulgaris' was used to determine the CMI response of experimental birds. PHA-P will provoke responses, influenced by the suspension of T-helper and T- suppressor cells. Good responder to PHA-P indicates a higher general level of cellular immunity influencing T-cell mechanisms restricting or preventing lymphoma formation.

Four (4) birds per sire (Total- 40 sires/variety) were selected and marked properly for easy identification, in which PHA-P $0.02 \mathrm{ml}(0.1 \mathrm{mg} / 0.02 \mathrm{ml}$ PBS) was interred digitally administered between the $3^{\text {rd }}$ and $4^{\text {th }}$ toe of the right foot of the quail. The left foot web of the same birds was injected (same route) with $0.02 \mathrm{ml}$ sterile PBS to serve as control. Before the injection the skin thickness of both left and right foot webs of the selected birds of each group were measured by a micrometer and the process is repeated after 24 hours of injection of mitogen. The foot web swelling in both foot webs were measured by subtracting the skin thickness at 24 hours from that of 0 hours of injection for respective foots.

Foot web index (FWI) expressed in mm was the value achieved after subtracting the difference in thickness of control (PBS injected) foot web at 0 and $24 \mathrm{hrs}$ from the difference in mitogen (PHA-P) injected foot web thickness at 0 and $24 \mathrm{hrs}$ of foot web. The in vivo CMI response (CMIR) of the injected birds to PHA-P mitogen was expressed as web index. The formula involved is as follows:

$$
\mathrm{CMIR}=(\mathrm{R} 2-\mathrm{R} 1)-(\mathrm{L} 2-\mathrm{L} 1)
$$

where, R2 = Thickness of right foot web after $24 \mathrm{~h}$ (1d) of PHA-P injection; R1 = Thickness of right foot web before injection of PHA-P (At 0h); L2 = Thickness of left foot web after $24 \mathrm{~h}$ (1d) of PBS injection; L1 = Thickness of left foot web before injection of PBS (At $0 \mathrm{~h}$ )

\section{Statistical analysis}

The least squares mean determination was analysed by JMP, mixed effect model Version 14.0. Variance components were assessed by Wombat (Full sib analysis) mixed model analysis by Restricted Maximum Likelihood (REML) using an animal model. The data were classified in accordance with the variety of the Japanese quail (CARI-
Ujjawal; CARI-Suneheri and CARI-Brown), hatch ( ${ }^{\text {st }}$, $2^{\text {nd }}, 3^{\text {rd }}$ hatches), Sex (male and female).

The data available was subjected to the following Model as,

$$
Y_{i j k l m}=\mu+S_{i}+V_{j}+H_{k}+S e_{l}+e_{i j k l m}
$$

Where as,

$Y_{i j k l m}$ : the observation of $k^{\text {th }}$ individual; $\mu$ : the overall populations mean; $S_{i}$ : the effect of $i^{\text {th }}$ sire; $\mathrm{V}_{j}$ : the effect of $j^{\text {th }}$ variety; $\mathrm{H}_{k}$ : the effect of $\mathrm{k}^{\text {th }}$ hatch; $\mathrm{Se}_{l}$ : the effect of $l^{\text {th }}$ sex; $e_{i j k l m}$ : the random error particular to $i j k l m^{\text {th }}$ individual.

\section{RESULTS AND DISCUSSION}

Least-squares means and standard errors by variety, sex and hatch for immune traits were revealed in Table 1. The mean for HA titre values in CARI-UJJAWAL, CARISUNEHERI and CARI-BROWN were $0.403 \pm 0.04$, $0.377 \pm 0.04$ and $0.384 \pm 0.04$ respectively. The present estimates were likewise to the reports of Srinivasan et al. (2006) in Japanese quail who obtained HA titre 4.03 - 4.17 for CARI developed varieties of Japanese quails.

Non genetic effects such as effect of variety, sex and hatch were shown in the Table 1 . In the current study, SRBC response were significantly $(\mathrm{p}<0.01)$ affected by varieties. These findings were in harmony with Srinivasan et al. (2006) and Devi et al. (2010). CARI-Ujjawal had high titre values than other two varieties. Sex had no significant effect on SRBC ( $>>0.01)$. These findings were similar to Saxena (1993) in chickens and guinea fowls, Sivaraman (2004) in SDL chickens, Srinivasan et al. (2006) in CARI-UJJAWAL; Devi et al. (2010) in black and brown strain of quails. These were disagreement with Vanderzijpp and Leenstra (1980) who observed variation in SRBC responses due to variety and sex also. There were significant differences between hatches $(p<0.01)$ for the results of SRBC. But this was disagreement with Devi et al. (2010) who reported that significant hatch effect was found for SRBC response with higher means recorded in $8^{\text {th }}$ hatch $(5.29)$ than those in the $9^{\text {th }}$ hatch $(4.63)$.

The overall means for foot pad index of CARI-UJJAWAL, CARI-SUNEHERI and CARI-BROWN were presented in the table 1. The foot pad index was more in CARIUJJAWAL variety $(0.42 \mathrm{~mm})$ over the CARI-SUNEHERI 
Table 1: Least mean square for immunocompetence traits - HA titre and Cell mediated immunity of Japanese quails

\begin{tabular}{|c|c|c|c|c|c|c|}
\hline \multirow{2}{*}{ ATTRIBUTE } & \multirow{2}{*}{$\mathbf{N}$} & \multicolumn{2}{|c|}{ HA TITRE $\left(\log ^{2}\right)$} & \multirow{2}{*}{$-\mathbf{N}$} & \multicolumn{2}{|c|}{ CMI (mm) } \\
\hline & & MEAN & $\pm \mathbf{S E}$ & & MEAN & $\pm \mathrm{SE}$ \\
\hline OVER ALL & 480 & 3.86 & 0.04 & 480 & 0.44 & 0.01 \\
\hline \multicolumn{7}{|l|}{ VARIETY } \\
\hline $\begin{array}{l}\text { CARI-UJJAWAL } \\
\text {. }\end{array}$ & 160 & $4.03^{\mathrm{b}}$ & 0.04 & 160 & $0.46^{\mathrm{b}}$ & 0.01 \\
\hline CARI-SUNEHERI & 160 & $3.77^{\mathrm{a}}$ & 0.04 & 160 & $0.42^{\mathrm{ab}}$ & 0.01 \\
\hline CARI-BROWN & 160 & $3.84^{\mathrm{a}}$ & 0.04 & 160 & $0.33^{\mathrm{a}}$ & 0.01 \\
\hline \multicolumn{7}{|l|}{ НATCH } \\
\hline I & 160 & $3.75^{\mathrm{x}}$ & 0.04 & 160 & 0.38 & 0.01 \\
\hline II & 160 & $3.83^{\mathrm{x}}$ & 0.04 & 160 & 0.44 & 0.01 \\
\hline III & 160 & $3.98^{\mathrm{y}}$ & 0.04 & 160 & 0.43 & 0.01 \\
\hline \multicolumn{7}{|l|}{ SEX } \\
\hline M & 250 & 3.84 & 0.03 & 250 & 0.44 & 0.01 \\
\hline $\mathrm{F}$ & 230 & 3.84 & 0.03 & 230 & 0.46 & 0.01 \\
\hline \multicolumn{7}{|l|}{ P VALUE } \\
\hline VARIETY & 0.0001 & & & 0.0001 & & \\
\hline HATCH & 0.0001 & & & 0.2273 & & \\
\hline SEX & 0.5284 & & & 0.9357 & & \\
\hline
\end{tabular}

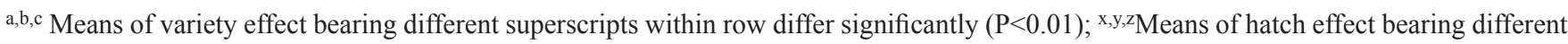
superscripts within column differ significantly $(\mathrm{P}<0.01)$.

Table 2: Heritability and standard error estimates of immune traits

\begin{tabular}{lll}
\hline Variety & HA TITRE & PHAP TITRE \\
\hline CARI-UJJAWAL & $0.258 \pm 0.088$ & $0.116 \pm 0.079$ \\
CARI-SUNEHERI & $0.443 \pm 0.086$ & $0.011 \pm 0.073$ \\
CARI-BROWN & $0.435 \pm 0.071$ & $0.171 \pm 0.084$ \\
\hline
\end{tabular}

HA- Haemagglutination, PHAP- Phytohaemagglutinin type P.

$(0.42 \mathrm{~mm})$ and CARI-BROWN $(0.33 \mathrm{~mm})$. These values were nearer and in good confirmation with the values noted by Seema Hood et al. (2005). The mean values of the response to cell-mediated immunity were comparable to the reports of Manwar et al. (2003) in Japanese quail where they observed $0.39 \pm 0.059 \mathrm{~mm}, 0.36 \pm 0.047$ for good and poor layers respectively. In the present investigation, foot pad index response were significantly $(p<0.01)$ affected by varieties. CARI-Ujjawal had high values than other two varieties. These findings were in harmony with Srinivasan et al. (2006) and Devi et al. (2010). But no significant difference was observed due to the effect of sex. This results was in consonance with Saxena et al. (1997) observed nonsignificant of sex on
CMI response in broiler and Kadaknath chicken, also been reported Ahmed (2001) in SDL broiler chicken and Singh (2003) in white turkey variety. There were no significant differences between hatches for the results of PHA-P mitogen. This was in the contrary case with Shakunthala et al. (2010) who reported that significant hatch effect was found for foot pad index with higher means recorded in $9^{\text {th }}$ hatch $(0.24 \mathrm{~mm})$ than those in the $8^{\text {th }}$ hatch $(0.18 \mathrm{~mm})$. The non-genetic effects such as effect of sex and hatch shows no significant differences in the CMI response study but variety shows. Not much variation observed in this response, could be due to the age of CMI response conducted in this study was higher ( $7^{\text {th }}$ week), as in our varieties the foot web at $5^{\text {th }}$ week (age for CMI response 
in chicken) exhibited much thinner which cannot able to take the drug so we performed the study at $7^{\text {th }}$ week. This indicates that the PHA-P response was decreased with advance in age. Whenever possible, age should be included as a covariate when the PHA-P skin test is used to assess immunocompetence in ecological immunology.

Estimates of heritability for immune related traits of three Japanese quail varieties are shown in Table 2 . According to the current study, the heritability estimates are grouped as below 0.2 as low heritable traits, $0.2-0.4$ as moderately heritable and 0.4 or more as highly heritable traits. The heritability estimates for SRBC, was high values (0.43-0.44) for CARI-SUNEHERI and CARIBROWN varieties. However in CARI- UJJAWAL, SRBC response was moderately heritable $(0.25)$. The heritability estimates of antibody titre against SRBC were moderate to high which is in agreement to the values reported in WPR chicken (Vander Zijpp et al., 1983), 0.36 \pm 0.17 in guinea fowl varieties (Saxena, 1993) and 0.349 \pm 0.309 in SDL broiler chicken by Ahmed (2001). MohammadiTighsiah et al. (2018) reported lower inheritance (0.21) of antibody titre in Japanese quail. The differences between reported heritability estimates may depend upon the population, environmental conditions, the method of estimation (Falconer and Mackay, 1996), statistical model and sampling error due to small data set or sample size (Prado-Gonzalez et al., 2003). Environmental and poor managemental conditions are known to increase the residual variance and decrease the heritability estimate (Singh et al., 2018). The heritability estimates observed in the present investigation revealed that the antibody titres in CARI-SUNEHERI, CARI- BROWN and CARIUJJAWAL varieties were influenced by genetic variation and existence of a distinct additive component which can be improved through selection of sires for disease resistance.

Inheritance of PHA-P mitogen for CARI-UJJAWAL, CARI-SUNEHERI and CARI-BROWN were 0.116; 0.011 and 0.171 . Literature revealed low heritability estimates (0.01-0.18) of PHA-P mitogen were similar to our reports (Saxena 1993; Cheng et al. 1994; Chao and Lee. 2000; Sivaraman 2004; Srinivasan 2006). The low heritability of foot pad index revealed that immune cell (T-cells) proliferative activity has low genetic variation in this population and offered less scope for its progress through selection of sires.

\section{CONCLUSION}

The immunocompetence status of SRBC of these stocks was moderate to high heritability values suggests that appropriate selection intervention such as individual selection can be executed which can positively improve the antibody production against antigens in Japanese quails. However in foot pad index response whose heritability values are low, indirect selection may help to improve cell mediated immunity.

\section{ACKNOWLEDGMENTS}

The authors are most grateful to ICAR-CARI and also Experimental Quail Farm-CARI, Izzatnagar for providing the necessary facilities for conducting the experiment.

\section{REFERENCES}

Ahmed, S., Ihara, K., Kanemitsu, S., Nakashima, H., Otsuka, T., Tsuzaka, K., Takeuchi, T. and Hara, T. 2001. Association of CTLA-4 but not CD28 gene polymorphisms with systemic lupus erythematosus in the Japanese population. Rheumatology, 40(6): 662-667.

Barbieri, A., Ono, R.K., Cursino, L.L., Farah, M.M., Pires, M.P., Bertipaglia, T.S., Pires, A.V., Cavani, L., Carreño, O.D. and Fonseca, R. 2015. Genetic parameters for body weight in meat quail. Poult. Sci., 94: 169-171.

Chao-ching, Hsien, Lee, Y.P., Chao, C.H. and Lee, Y.P., 2000. Response to two generations of divergent selection for serum gamma-globulin percentage in Taiwan country chicken. $J$. Chin. Soc. Anim. Sci., 29(3): 287-298.

Cheng, K.M., Pang, C.S., Wang, Z.P., Yuan, H., Nichols, C.R., Brown, G.M. and Pang, S.F. 1994. A Comparison of $\left({ }^{125} \mathrm{I}\right)$ iodo-melatonin binding sites in testes and brains of heavy meat-type Japanese quail with a random bred strain. $J$. Heredity, 85(2): 136-139.

Corrier, D.E. and Deloach, J.R. 1990. Evaluation of cell-mediated cutaneous basophil hypersensitivity in young chickens by an interdigital skin test. Poult. Sci., 69: 403-408.

Devi, K.S., Gupta, B.R., Gnanaprakasah, M., Qudratullah, S. and Reddy, A.R. 2010. Inheritance of growth and immunocompetence traits in Japanese quails under long-term selection. Indian J. Vet. Anim. Sci., 6(3): 111-116.

Falconer, D.S. and Mackay, T.F.C. 1996. Introduction to quantitative genetics. Fourth Edition, Pearson India Education Services Pvt. Ltd, UP, India, pp. 160-181.

Gavora, J.S. and Spencer, J.L. 1983. Breeding for immune responsiveness and disease resistance. Anim. Blood Groups Biochem Genet., 14(3): 159-180. 
Genchev, A., Mihaylova, G., Ribarski, S., Pavlov, A. and Kabakchiev, M. 2008. Meat quality and composition in Japanese quails. Trakia J. Sci., 6(4): 72-82.

Lamont, S.J. 1998. Impact of genetics on disease resistance. Poult. Sci., 77(8): 1111-1118

Manwar, S.J., Moudgal, R.P., Sastry, K.V.H., Tyagi, I.S. and Saxena, Y.K. 2003. Nitric oxide regulating immune functions in egg type Japanese quail. Indian J. Poult. Sci., 38(2): 133136.

Mohammadi-Tighsiah, A., Maghsoudi, A., BagherzadehKasmani, F., Rokouei, M. and Faraji-Arough, H. 2018. Bayesian analysis of genetic parameters for early growth traits and humoral immune responses in Japanese quail. Livest. Sci., 216: 197-202.

Prado-Gonzalez, E.A., Ramirez-Avila, L. and Segura-Correa, J.C. 2003. Genetic parameters for body weights of Creole chickens from Southeastern Mexico using an animal model. Livest. Res., 15(1): 27-31.

Saatci, M., Omed, H. and ApDewi, I. 2006. Genetic parameters from univariate and bivariate analyses of egg and weight traits in Japanese quail. Poult. Sci., 85(2): 185-190.

Saxena, V.K. 1993. Genetic studies on immunocompetence in guinea fowl (Numida meleagris). Ph.D. Thesis, Indian Veterinary Research Institute (Deemed University).

Saxena, V.K., Singh, H., Pal, S.K. and Kumar, S. 1997. Genetic studies on primary response to sheep erythrocytes in guinea fowl. Br. Poult. Sci., 38: 156-158.

Hood S., Praveen, K., Tyagi, P., Tyagi K. and Sharma D. 2005. Effect of higher dietary concentration of alpha tocopherol on growth performance and immune response in growing quails. Indian J. Poult. Sci., 40(1): 32-35.

Siegel, P.B. and Gross, W.B. 1980. Production and nonpersistence of antibodies in chicken to sheep erythrocytes. 1 . Directional Selection. Poult. Sci., 59: 1-5.
Singh, M.K., Kumar, S., Sharma, R.K., Singh, S.K., Singh, B. and Singh, D.V. 2018. Genetic evaluation of egg quality traits in Uttara fowl using MMLSML. Indian J. Poult. Sci., 53(1): $15-20$.

Singh, N.S., Kumar, S. and Majumdar, S. 2003. Genetic studies of growth traits in White Turkey line selected for high humoral immune response. J. Appl. Anim. Res., 24(2): 193200.

Sivaraman, G.K. 2004. Molecular genetic evaluation of broiler chicken line divergently selected for immunocompetence index. Doctoral dissertation submitted to Deemed University, IVRI, Izatnagar (U.P.) India.

Srinivasan, D. 2006. Genetic analyses of humoral and specific immunocompetence in three Japanese quail populations. M.V.Sc., Thesis submitted to Deemed University, IVRI, Izatnagar (U.P.) India.

Van der Most, P.J., de Jong, B., Parmentier, H.K. and Verhulst, S. 2011. Trade-off between growth and immune function: a meta-analysis of selection experiments. Funct. Ecol., 25(1): 74-80.

Van der Zijpp, A.J., Frankena, K., Boneschanscher, J. and Nieuwland, M.G.B. 1983. Genetic analysis of primary and secondary immune responses in the chicken. Poult. Sci., 62(4): 565-572.

Van Der Zijpp, A.J. and Leenstra, F.R. 1980. Genetic analysis of the humoral immune response of White Leghorn chicks. Poult. Sci., 59: 1363-1369. 
